\title{
Reinforcing effects of smoked methamphetamine in rhesus monkeys
}

\author{
Jennifer L. Newman • Marilyn E. Carroll
}

Published online: 10 October 2006

(C) Springer-Verlag 2006

The online version of the original article can be found at: http://dx.doi. org/10.1007/s00213-006-0479-z.

J. L. Newman $(\bowtie) \cdot$ M. E. Carroll

Department of Psychiatry,

University of Minnesota Medical School,

MMC 392,

Minneapolis, MN 55455, USA

e-mail: newma210@umn.edu
Psychopharmacology (2006) 188:193-200

Unfortunately, one of the author's corrections was not carried out. Discussion section, 6th paragraph, third sentence should read:

METH produces a slower onset of subject-rated effects that remain elevated for a longer period of time relative to $\mathrm{COC}$, which produces rapid peak levels of subjective effects that dissipate earlier. 